\title{
Comparison of two soya bean simulation models under climate change. II. Application of climate change scenarios
}

\author{
Joost Wolf* \\ Department of Soil and Land Use, ALTERRA, PO Box 47, 6700 AA Wageningen, The Netherlands
}

\begin{abstract}
The effects of climate change (for 2050 compared to ambient climate) and change in climatic variability on soya bean growth and production at 3 sites in the EU have been calculated. These calculations have been done with both a simple growth model, SOYBEANW, and a comprehensive model, CROPGRO. Comparison of the results from the 2 models indicated the sort of climate change conditions in which model results differed and may become less reliable. The effectiveness of possible management responses to climate change and the uncertainty in the model results were also evaluated with both models. Both models calculated for the climate change scenarios at Oxford a strong increase in irrigated seed yield. For Montpellier and Seville, however, CROPGRO calculated a considerable increase in irrigated yield for these scenarios, whereas SOYBEANW calculated only a slight increase. Without irrigation, the seed yield increase for the climate change scenarios was almost identical for the 2 models, i.e. considerable, slight and nil for Oxford, Montpellier and Seville, respectively. Changes in climatic variability did not result in a yield change at any site, both with and without irrigation and both for CROPGRO and SOYBEANW. With irrigation, the change in the coefficient of variation (CV) of seed yields by climate change was nil (except for decrease at Oxford) for both models and without irrigation, this change in CV was variable depending on site, climate change scenario and model. The management response analyses showed that the crop variety did not need to be changed in response to climate change, that the yield increase due to climate change was stronger for an advanced sowing date (but only without irrigation), and that irrigation requirements decreased with climate change only in the case of an early sowing date. This pointed to the need for advancing the sowing date with climate change. The uncertainty analyses showed that the yield change due to climate change was practically not affected by the used crop variety and soil type, but that this yield change may become different when a different growth model was applied or a different sowing date was chosen.
\end{abstract}

KEY WORDS: Climate change $\cdot$ Climatic variability $\cdot$ Model comparison $\cdot$ Risk assessment $\cdot$ Scenario analyses $\cdot$ Simulation model $\cdot$ Soya bean

\section{INTRODUCTION}

Climate change, which may result from increasing concentrations of greenhouse gases in the atmosphere (Mearns 2000), could considerably affect growth and yield of most crops (Adams et al. 1990, Easterling et al. 1992a,b) and also of soya bean (Curry et al. 1990, 1995,

*E-mail: j.wolf@alterra.wag-ur.nl
Haskett et al. 1997). In the present study soya bean growth was simulated with 2 models under climate change conditions in the EU. The applied soya bean models are SOYBEANW, a revised version of a simple soya bean model (Sinclair 1986) and the comprehensive CROPGRO model (Jones et al. 1989, Tsuji et al. 1994, Hoogenboom et al. 1995, Boote et al. 1998a,b). The simple soya bean model has been tested and applied under ambient conditions (Muchow \& Sinclair 1986, Spaeth et al. 1987, Sinclair et al. 1992) and has 
also been applied to projected future changes in climatic conditions in the USA (Sinclair \& Rawlins 1993). CROPGRO has been validated and applied under a large range of ambient environmental conditions (Jones \& Ritchie 1991, Egli \& Bruning 1992, Nagarajan et al. 1993, Hoogenboom et al. 1997) and has also been applied to projected future climate conditions in the USA (Curry et al. 1990, 1995, Pickering et al. 1995), in India (Lal et al. 1999) and Argentina (Magrin et al. 1997). The main characteristics of and differences between the 2 models have been described by Wolf (2002, in this issue). Also other crop models, such as EPIC and GLYCIM, have been applied to assess the impact of climate change on soya bean production in the USA (Phillips et al. 1996, Haskett et al. 1997). However, the climate change impacts on soya bean production in Europe have not yet been calculated.

Both models were calibrated and validated against results from soya bean trials at Toulouse, France. Subsequently, the sensitivity of model results to separately changed values of weather variables was determined. These validation and sensitivity analyses were described by Wolf (2002). Both models have been applied to analyse the possible effects of climate change on soya bean production in the EU. In addition to the mean change in climate, the variability of the climate may alter in the future (Rind et al. 1989, Mearns 2000). As mean crop yields may decrease with increasing climatic variability and the yield variability between years and the risk of a relatively low yield may concurrently increase (Semenov \& Porter 1995, Semenov et al. 1996), the possible effects of changes in climatic variability on soya bean production were analysed too. Changed climate conditions may require a change in crop management, such as a change in sowing date or a switch to a new variety. The effectiveness of such management responses to a changed climate were evaluated using the results from both models. The uncertainties that are incorporated in this climate change impact study were analysed.

More information on this study that formed part of the EU project CLIVARA (focussed on the effects of climate change and climatic variability on the growth and yield of 4 crop species in Europe) is given in the final report of this project (Downing et al. 2000, Wolf 2000a).

\section{METHODOLOGY}

CROPGRO contains more elaborate descriptions of crop growth, assimilate allocation, leaf area expansion, phenology, senescence of crop organs, water balance, sink limitation, stress effects on assimilate production and allocation and on senescence than does SOY-
BEANW. For a description of the main characteristics of both models, such as the main processes included and the input data required, see Wolf (2002). As the number of growth processes described in CROPGRO is much larger, the sensitivity to changes in environmental conditions may become more complex and may differ from that described in SOYBEANW.

For model simulations of future soya bean production, future weather data were required. Results from 2 of the Hadley Centre's climate model (HADCM2) transient experiments have been used to construct climate change scenarios for sites in Europe (Barrow et al. 2000). HADCM2 is a fully coupled ocean-atmosphere global climate model to investigate the response of the climate system to increasing levels of greenhouse gases and sulphate aerosols (Mitchell et al. 1995, Johns et al. 1997). The first HADCM2 experiment considered only the effects of increases in greenhouse gases on the climate (HCGG scenario) and the second experiment took into account both increases in greenhouse gases and in sulphate aerosols, which resulted in a smaller warming effect (HCGS scenario). The HCGG and HCGS climate changes (for the period around 2050) over Europe resulted in slight and variable changes in radiation, in slight increases in precipitation (except for a slight decrease in precipitation for HCGG climate change in southern Europe, mainly during summer), and in European-mean temperature rises by respectively 2.3 and $1.5^{\circ} \mathrm{C}$. These temperature rises varied between sites without clear patterns and were slightly stronger during winter than during summer.

Daily weather data, as required for the future growth simulations, were produced with the LARS-WG stochastic weather generator (Semenov \& Barrow 1997). For each site, parameter values of the generator were first calibrated on the basis of historical weather data and subsequently adjusted on the basis of the sitespecific climate change results from the HADCM2 experiments. For more information on this method for constructing climate change scenarios, see Barrow et al. (2000). Analyses of the daily data from the HADCM2 experiments allowed changes in climatic variability to be included in the generated weather data sets.

CROPGRO and SOYBEANW were applied at 3 sites which represent the range of climatic conditions that is suitable for future soya bean production in the EU: Oxford, UK; Montpellier, France; and Seville, Spain. For these sites the effects on soya bean production of climate change and change in climatic variability were calculated. The model simulations were made for 30 years of generated weather data for baseline climate (the period around 1975), for 30 years of generated weather data for the HCGG and for the HCGS scenario climates (the period around 2050), and for the 
latter scenario climates with incorporated changes in the climatic variability, i.e. HCGGv and HCGSv. For the baseline climate the atmospheric $\mathrm{CO}_{2}$ concentration was set at $353 \mathrm{ppmv}$ and for the 4 scenario climates at 515 ppmv. Reported values for each output variable are the mean result of 30 years of growth simulations.

Both applied models were calibrated against soya bean trials at Toulouse, France (Colson 1992, Colson et al. 1995), as described by Wolf (2002). For the cooler conditions at Oxford a crop variety with a faster phenological development (SOYBEANW: thermal time requirement for the period until the start of seed filling reduced by $15 \%$ and the period of seed filling determined by self-destruction of the plant [see Wolf 2002]; CROPGRO: thermal time requirements for all phenological phases reduced by $15 \%$ and reduced long-day effect) than at the other sites was used and the sowing date was set 10 d later (i.e. Day 120). For the climate change scenario analyses crop varieties were identical to those used under the baseline conditions. In the management response analyses the crop variety did not change with increasing advancement of the sowing date. In these analyses the mid crop variety is identical to that calibrated against the soya bean trials at Toulouse (Wolf 2002). The early, late and very late varieties have thermal time requirements that are respectively $15 \%$ lower and 15 and $30 \%$ higher than those of the mid crop variety (CROPGRO: unchanged long-day effect; SOYBEANW: period of seed filling determined by self-destruction). This difference in phenological development rate between varieties may of course be caused by differences in photoperiod sensitivity too, but that was not analysed in this study. For all sites an identical soil type (i.e. medium soil texture, e.g. loamy sand, with $150 \mathrm{~mm}$ maximum available water in rooted zone) was used.

\section{RESULTS}

Both models were applied to analyse the possible effects of climate change and changes in climatic variability on soya bean production. Changed climate conditions may require a change in crop management. The effectiveness of such management responses to a changed climate were evaluated using the results from both models. The uncertainties incorporated in this climate change impact study were analysed.

\subsection{Scenario analyses}

CROPGRO and SOYBEANW were applied at 3 sites in the EU: Oxford, Montpellier and Seville. For irrigated

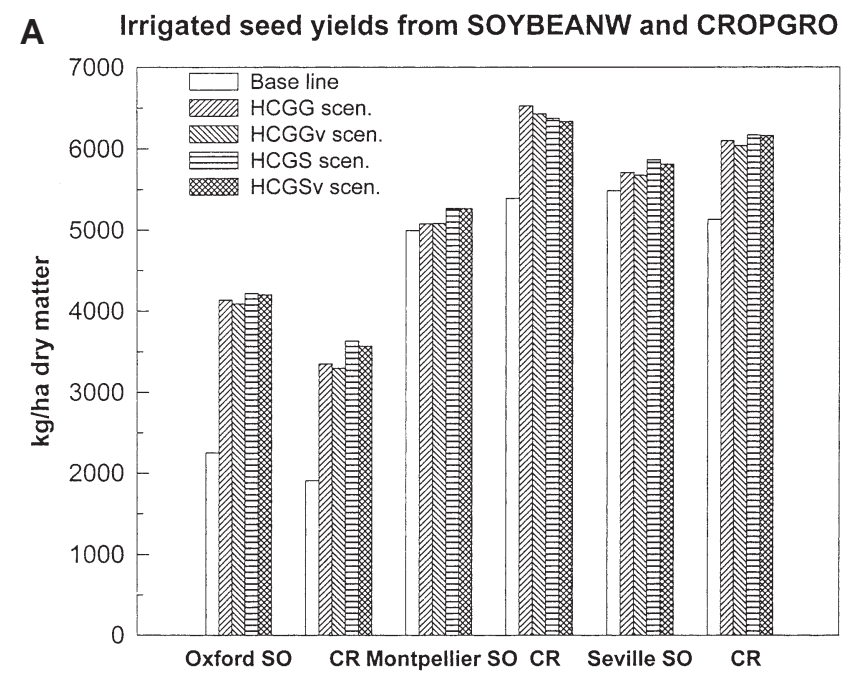

B Seed yields (not irrigated) from SOYBEANW and CROPGRO

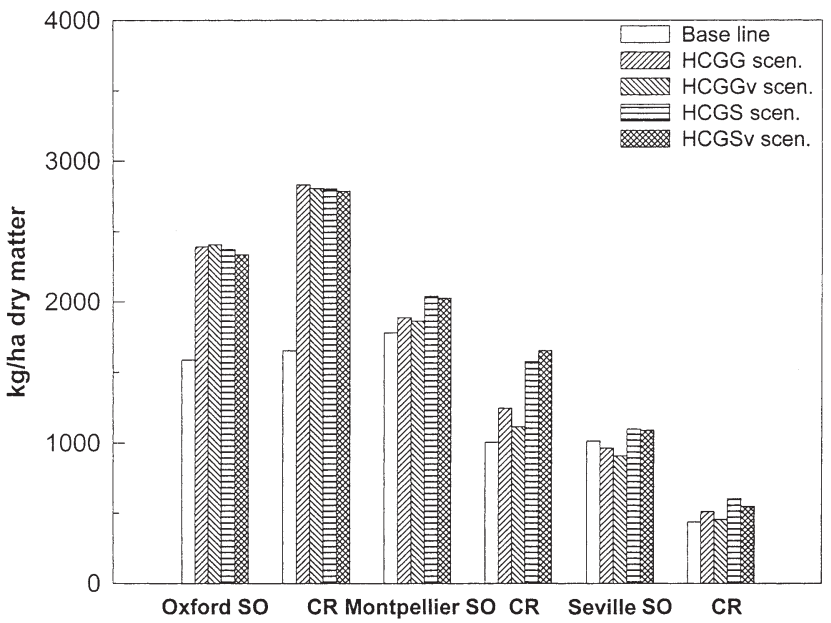

Fig. 1. Seed yields of soya bean calculated with CROPGRO (CR) and SOYBEANW (SO) for present and future climate conditions at 3 sites in the EU, both (A) with and (B) without irrigation. Results refer to 30 years of generated weather data for baseline climate and 4 climate change scenarios

production both models calculated similar seed yields for the baseline conditions at all sites (Fig. 1). Without irrigation, the seed yields at Oxford were identical for both models, showing a slight yield reduction as a result of water limitation. For baseline conditions at Montpellier and Seville CROPGRO calculated much lower waterlimited yields than SOYBEANW. This was caused by the difference in the modelled yield sensitivity to water shortage, as shown by Wolf (2002). Both models calculated for the HCGG and HCGS climate change scenarios a strong and very significant increase in seed yield for irrigated production at Oxford (Fig. 1, Table 1). At Montpellier and Seville, CROPGRO calculated a considerable yield increase for these scenarios, and SOYBEANW only 
Table 1. Statistical significance of the effect of climate change scenarios on seed yields of soya bean calculated with SOYBEANW and CROPGRO for 3 sites in the EU. +: positive changes in yield; -: negative changes ; 0: no change. Double symbols indicate significance at the $1 \%$ level and single symbols at the $5 \%$ level. A = effect of climate change scenario in comparison to baseline climate; $\mathrm{B}=$ effect of change in climatic variability (e.g. HCGGv vs HCGG)

\begin{tabular}{|c|c|c|c|c|c|c|c|c|c|c|c|c|}
\hline & \multicolumn{6}{|c|}{ Irrigated production } & \multicolumn{6}{|c|}{ Non-irrigated production } \\
\hline & HCGG & HCGGv & HCGGv & HCGS & HCGSv & HCGSv & HCGG & HCGGv & HCGGv & HCGS & HCGSv & HCGSv \\
\hline & A & B & & A & B & A & B & & A & B & & \\
\hline \multicolumn{13}{|l|}{ SOYBEANW } \\
\hline Oxford & ++ & ++ & 0 & ++ & ++ & 0 & ++ & ++ & 0 & ++ & ++ & 0 \\
\hline Montpellier & 0 & 0 & 0 & ++ & ++ & 0 & 0 & 0 & 0 & 0 & 0 & 0 \\
\hline Seville & ++ & + & 0 & ++ & ++ & 0 & 0 & 0 & 0 & 0 & 0 & 0 \\
\hline \multicolumn{13}{|l|}{ CROPGRO } \\
\hline Oxford & ++ & ++ & 0 & ++ & ++ & 0 & ++ & ++ & 0 & ++ & ++ & 0 \\
\hline Montpellier & ++ & ++ & 0 & ++ & ++ & 0 & 0 & 0 & 0 & + & + & 0 \\
\hline Seville & ++ & ++ & 0 & ++ & ++ & 0 & + & 0 & 0 & ++ & ++ & 0 \\
\hline
\end{tabular}

A

CV of irrigated seed yields from SOYBEANW and CROPGRO

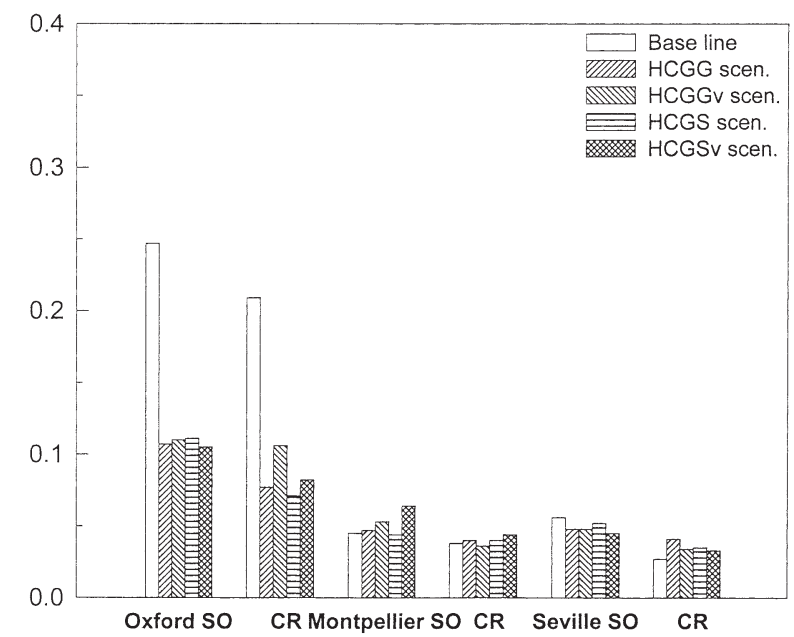

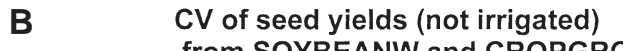
from SOYBEANW and CROPGRO

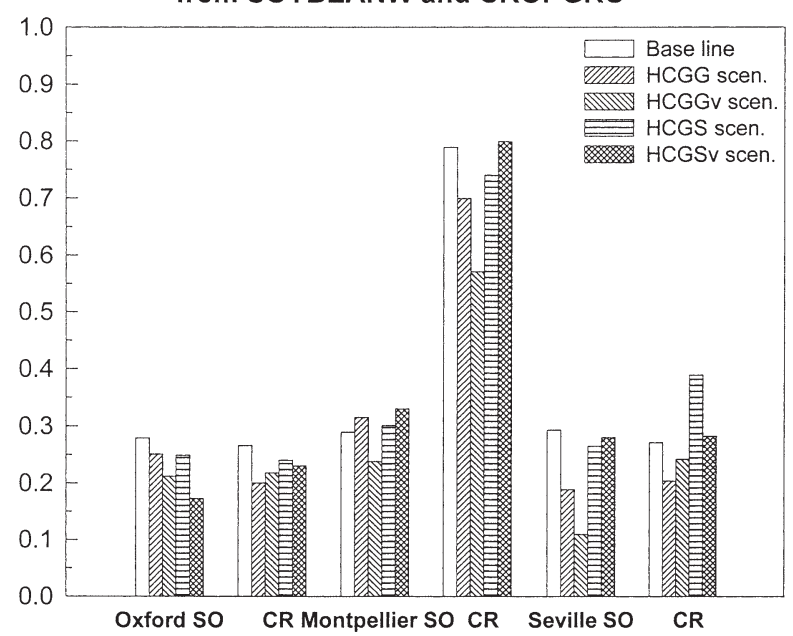

Fig. 2. Coefficient of variation (CV) of seed yields of soya bean calculated with CROPGRO (CR) and SOYBEANW (SO) for present and future climate conditions at 3 sites in the EU, both (A) with and (B) without irrigation. Results refer to 30 years of generated weather data for baseline climate and 4 climate change scenarios

a slight increase. Without irrigation, the yield increase due to the climate change scenarios was almost identical for both models, being considerable (and very significant), slight and nil for Oxford, Montpellier and Seville, respectively. At both Montpellier and Seville this yield increase was strongly limited by increasing water shortage with climate change but not at Oxford. The absolute yield level at both Montpellier and Seville differed between the 2 models, as explained above for baseline conditions (due to different yield sensitivity to water shortage). Changes in climatic variability (HCGGv, HCGSv) did not result in a yield change at any site when compared with the HCGG and HCGS results, both with and without irrigation and with both CROPGRO and SOYBEANW.
Both models calculated very low values for the coefficient of variation $(\mathrm{CV}=$ standard deviation/average) of irrigated seed yield under the baseline climate at both Montpellier and Seville (Fig. 2). The CV values did not change with climate change. For Oxford both models calculated relatively high $\mathrm{CV}$ values for irrigated production. These CV values decreased with a change in the climate. Note that this decrease in CV was mainly caused by the increase in mean yield. Without irrigation, the CV of seed yield was moderately high under the baseline climate at all sites (except for the very high CV value for Montpellier from CROPGRO). CROPGRO calculated for the HCGG scenario a moderate decrease in the CV for nonirrigated seed yields at all sites, whereas SOYBEANW 
calculated a slight and moderate decrease for Oxford and Seville, respectively, and a slight increase for Montpellier. CROPGRO calculated for the HCGS scenario a slight decrease in the CV for Oxford and Montpellier and a moderate increase in Seville, whereas SOYBEANW calculated a slight decrease for Oxford and Seville and no change for Montpellier. Changes in climatic variability did not change $\mathrm{CV}$ values for irrigated yields from both models and resulted in nil to moderately lower $\mathrm{CV}$ values for the water-limited yields.

\subsection{Management response analyses}

Changed climate conditions may require a change in crop management, such as a change in sowing date or a switch to a new crop variety. Crop water use may also change which in dry regions may have consequences for irrigation water requirements. The effectiveness of such management responses to a changed climate was evaluated using the results from both soya bean models.

\subsubsection{Crop variety}

Irrigated seed yields were calculated with both CROPGRO and SOYBEANW for the baseline and scenario climates at Seville for 4 crop varieties, differing in their rate of phenological development (Fig. 3). The HCGG and HCGS scenarios gave moderate increases in seed yield with CROPGRO and slight increases with SOYBEANW. With both models, changes in climatic variability (HCGGv, HCGSv) did not give a yield change when compared with the HCGG and HCGS results. The impact of the crop variety on yield changes due to climate change was small to nil with both models. However, the absolute yield level varied considerably between crop varieties. Particularly with SOYBEANW, the later varieties gave a much higher seed yield. Sink limitation was not incorporated in this model which, compared with the yield from CROPGRO, resulted in a very high seed yield for the very late variety.

\subsubsection{Sowing date}

Irrigated and water-limited seed yields were calculated with both CROPGRO and SOYBEANW for baseline and scenario climates at Seville and for different sowing dates (Fig. 4). An advanced sowing date resulted in a nil and a considerable increase in seed yield for irrigated production from CROPGRO and SOY-

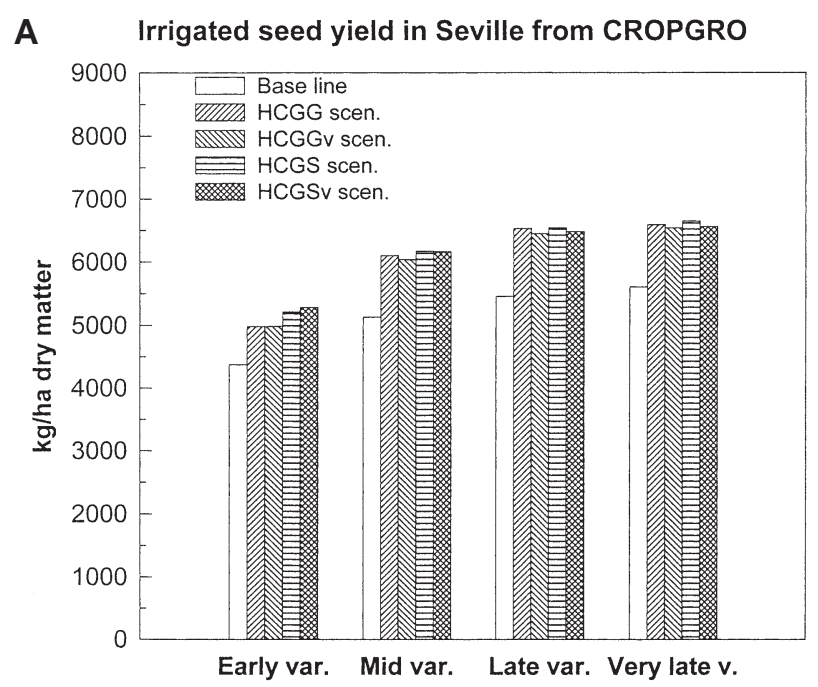

\section{B Irrigated seed yield in Seville from SOYBEANW}

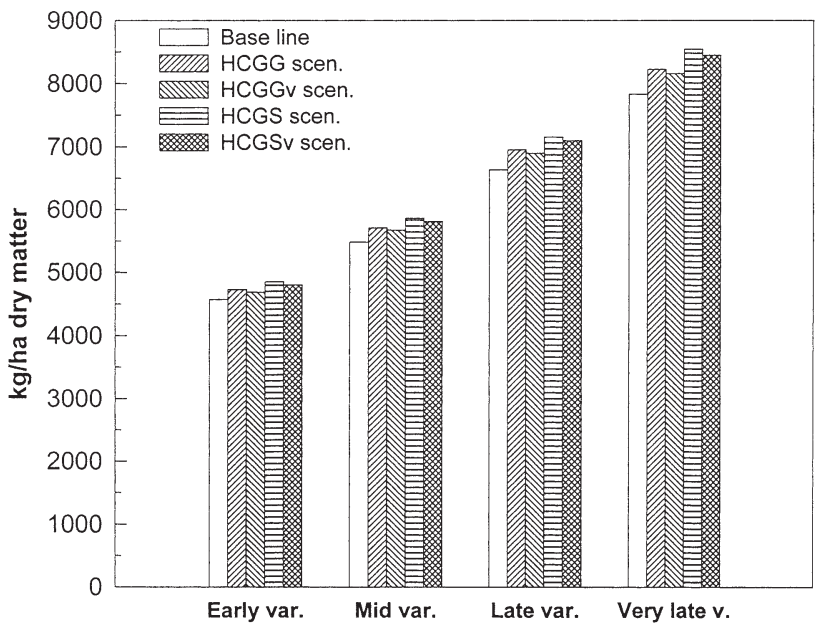

Fig. 3. Seed yields of 4 irrigated soya bean varieties calculated with (A) CROPGRO and (B) SOYBEANW for present and future climate conditions at Seville. Results refer to 30 years of generated weather data for baseline climate and 4 climate change scenarios

BEANW, respectively, both with and without climate change. With an earlier sowing date, the vegetative growth period occurred at lower temperatures and, hence, became longer, and this resulted in more biological nitrogen fixation and a higher seed yield with SOYBEANW. Such a positive effect of an advanced sowing date on the seed yield was not calculated with CROPGRO. The impact of an earlier sowing date on yield changes by climate change was nil according to both models, when irrigation was applied. For waterlimited production, an earlier sowing date resulted in a moderately and considerably higher seed yield for baseline and scenario climate, respectively with CROPGRO and a slightly and moderately higher yield 
A

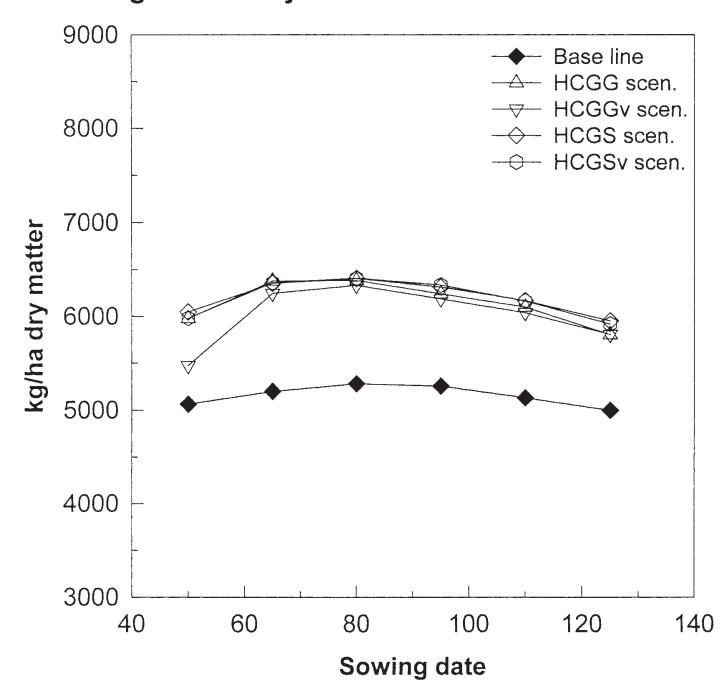

C Irrigated seed yield in Seville from SOYBEANW

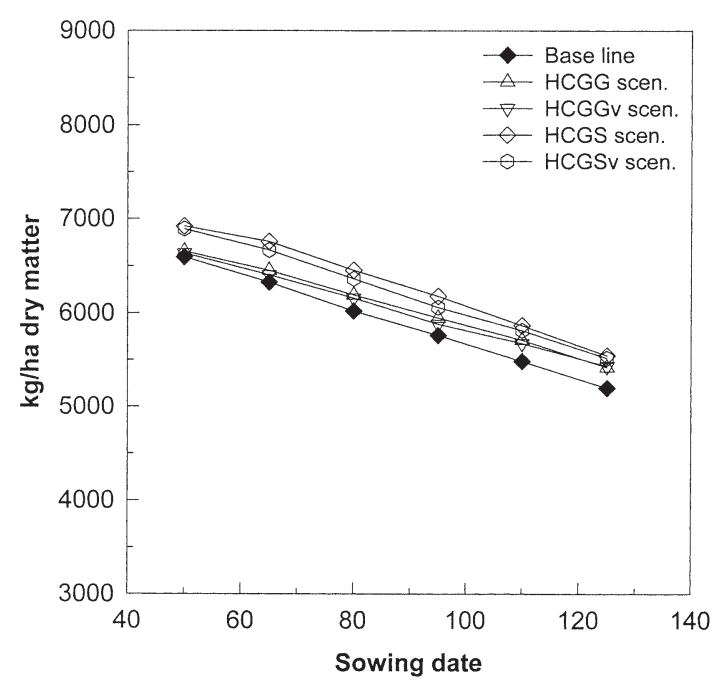

B Seed yield (not irrigated) in Seville from CROPGRO

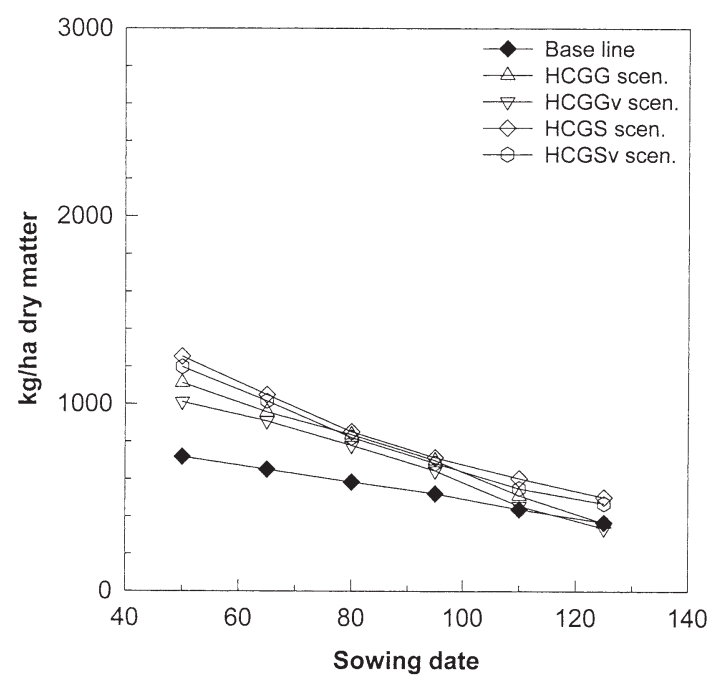

D Seed yield (not irrigated) in Seville from SOYBEANW

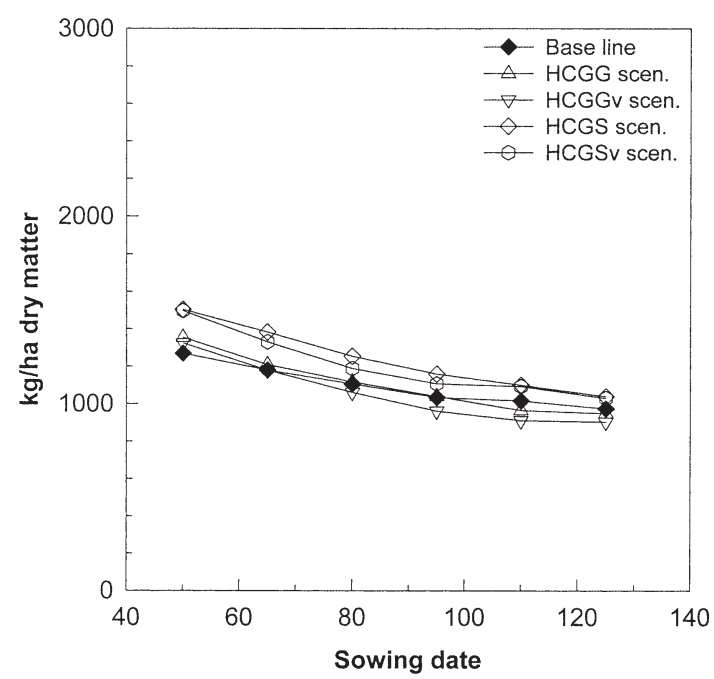

Fig. 4. Sensitivity to changes in sowing date (Julian day) of the seed yields of irrigated and non-irrigated soya bean as calculated with $(A, B)$ CROPGRO and $(C, D)$ SOYBEANW for present and future climate conditions at Seville. Results refer to 30 years of generated weather data for baseline climate and 4 climate change scenarios

with SOYBEANW. These results showed that for water-limited production the yield changes due to climate change were positively affected by advancement of the sowing date. The yield increase due to climate change from CROPGRO (due to its stronger yield sensitivity to drought; Wolf 2002) was affected more strongly by sowing date than that from SOYBEANW.

\subsubsection{Irrigation requirement}

The amount of irrigation water required for attaining the potential level of seed production was calculated with CROPGRO and SOYBEANW for the 3 sites in the
EU, both under the baseline and scenario climates (Table 2). SOYBEANW calculated slightly to moderately higher irrigation requirements for baseline conditions than CROPGRO (due to different evapo-transpiration method, see Wolf 2002). CROPGRO calculated for the HCGG climate change scenario a nil, slight and strong increase in irrigation requirements for Oxford, Montpellier and Seville, respectively, but SOYBEANW a moderate increase, a slight decrease and a moderate increase for these sites in the same order. For the HCGS scenario CROPGRO gave a moderate increase in irrigation requirements for Oxford and Seville and a moderate decrease for Montpellier, whereas SOYBEANW gave also a moderate increase for Oxford and 
Table 2. Amount of irrigation water $(\mathrm{mm})$ required for attaining the potential seed yield of soya bean on a soil with medium texture, calculated with CROPGRO and SOYBEANW for present and future climate conditions at 3 sites in the EU. Results refer to 30 years of generated weather data for baseline climate and 4 climate change scenarios

\begin{tabular}{|c|c|c|c|c|c|c|c|}
\hline \multirow{2}{*}{ Crop model } & \multirow[t]{2}{*}{ Site } & \multirow{2}{*}{ Sowing day } & \multirow{2}{*}{ Baseline climate } & \multicolumn{4}{|c|}{ Climate change scenarios } \\
\hline & & & & HCGG & HCGGv & HCGS & HCGSv \\
\hline \multirow[t]{3}{*}{ CROPGRO } & Montpellier & 110 & 330 & 341 & 349 & 304 & 299 \\
\hline & Oxford & 120 & 89 & 89 & 78 & 115 & 120 \\
\hline & Seville & 110 & 475 & 553 & 563 & 500 & 509 \\
\hline \multirow[t]{3}{*}{ SOYBEANW } & Montpellier & 110 & 338 & 327 & 329 & 309 & 306 \\
\hline & Oxford & 120 & 104 & 141 & 137 & 139 & 150 \\
\hline & Seville & 110 & 519 & 557 & 568 & 521 & 525 \\
\hline
\end{tabular}

Table 3. Required amount of irrigation water ( $\mathrm{mm}$ ) for attaining the potential seed yield of soya bean on a soil with medium texture, calculated with CROPGRO and SOYBEANW for present and future climate conditions at Seville and different sowing dates (Julian day). Results refer to $30 \mathrm{yr}$ of generated weather data for baseline climate and 4 climate change scenarios

\begin{tabular}{|c|c|c|c|c|c|c|}
\hline \multirow[t]{2}{*}{ Crop model } & \multirow[t]{2}{*}{ Sowing day } & \multirow[t]{2}{*}{ Baseline climate } & \multicolumn{4}{|c|}{-Climate change scenarios } \\
\hline & & & HCGG & HCGGv & HCGS & HCGSv \\
\hline \multirow[t]{3}{*}{ CROPGRO } & 50 & 450 & 429 & 408 & 428 & 433 \\
\hline & 80 & 476 & 505 & 539 & 480 & 501 \\
\hline & 110 & 475 & 553 & 563 & 500 & 509 \\
\hline \multirow[t]{3}{*}{ SOYBEANW } & 50 & 541 & 515 & 531 & 507 & 511 \\
\hline & 80 & 528 & 551 & 564 & 525 & 527 \\
\hline & 110 & 519 & 557 & 568 & 521 & 525 \\
\hline
\end{tabular}

a moderate decrease for Montpellier but no change for Seville. A change in climatic variability (HCGGv, HCGSv) resulted in slightly negative to slightly positive changes in the irrigation requirements when compared with the HCGG and HCGS results, and these changes in irrigation requirements were almost identical for the 2 models.

The effects of different sowing dates on irrigation requirements at Seville were calculated with the 2 models (Table 3). Advancement of the sowing date had with both models a slight effect on the irrigation requirements under the baseline climate. However, under the climate change scenarios, an advanced sowing date caused a strong reduction in irrigation requirements with CROPGRO and a slight to moderate reduction with SOYBEANW. Hence, the climate change scenarios resulted only for the earliest sowing date in decreases in irrigation requirements when compared with the baseline result.

\subsection{Model uncertainty analyses}

Both models have been applied to analyse the impact of climate change at the 3 sites in the EU. In this study, several uncertainties are incorporated. The following uncertainties and their possible effects on re- sults were analysed: (1) model structure and modelled yield sensitivity; (2) change in crop management (e.g. variety and sowing date); (3) quality of input data.

The structure of both soya bean models and their calibration and testing versus experimental data sets have already been described (Wolf 2002). The described differences between SOYBEANW and CROPGRO and the resulting differences in yield sensitivity to stepwise changes in climate gave an indication of the degree of uncertainty caused by the structure of the model. For example, the yield sensitivities to changes in most weather variables were practically the same for both models. Important model differences were the higher optimum temperature for irrigated seed production and the stronger seed yield reduction by water shortage in CROPGRO than in SOYBEANW. Under climate change the crop varieties best suited to an area may differ from the present varieties. Hence, growth simulations under climate change were conducted for different soya bean varieties. Also the effectiveness of other management responses to climate change (e.g. change in sowing date) were evaluated and results were given above (Section 3.2).

The quality of the results from climate change impact studies is greatly dependent on the quality of the input data. The sensitivity of the yields to changes in weather data (indicating the sensitivity to data un- 
certainty) has been described in the sensitivity analysis (Wolf 2002). Soil information generally is available qualitatively and is often aggregated into mixed soil units. This results in uncertainty about the quantitative soil characteristics (e.g. rooting depth, water-holding capacity). Growth simulations under climate change were conducted for different soil types to analyse this source of uncertainty.

Soya bean yields were calculated with both SOYBEANW and CROPGRO for baseline and scenario climate at Seville and for 3 soil types (Fig. 5), mainly differing with respect to the maximum available water in rooted zone (coarse $=60 \mathrm{~mm}$, medium $=150 \mathrm{~mm}$, optimal $=240 \mathrm{~mm}$ ). The results show that the change in

\section{A Seed yield (not irrigated) in Seville from CROPGRO}

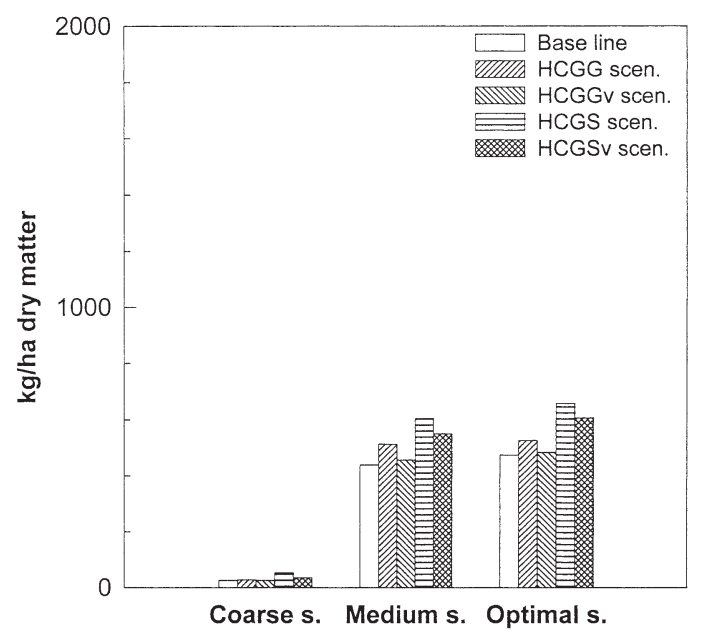

B Seed yield (not irrigated) in Seville from SOYBEANW

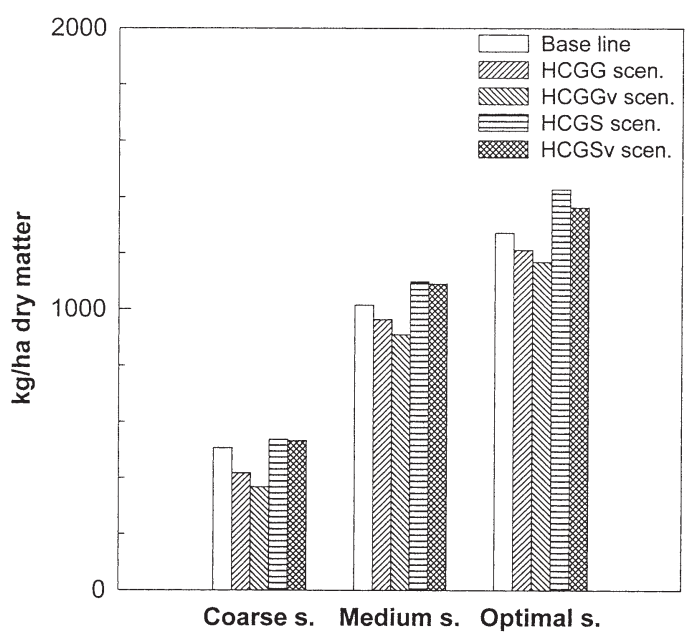

Fig. 5. Seed yields of soya bean (non-irrigated) calculated with (A) CROPGRO and (B) SOYBEANW for 3 soil types and present and future climate conditions at Seville. Results refer to 30 years of generated weather data for baseline climate and 4 climate change scenarios water-limited seed yield due to climate change was slightly different for the different climate change scenarios (compared with baseline yield) and was also slightly different for the 2 models. However, the impact of soil type on the yield change appeared to be almost nil for SOYBEANW results, although the absolute yield level was clearly different between soil types (i.e. higher yields on soils that were able to supply more water). This indicated that the interaction between yield change due to climate change and the soil type was practically nil for SOYBEANW results and that uncertainty about soil characteristics had almost no influence on the yield change. The CROPGRO results showed that the water supply on both medium and optimal soils was identical, being determined by the low amount of rainfall in Seville, and was too low on the coarse soil to attain any seed yield. Thus, from these results it cannot be determined whether or not the interaction between yield change due to climate change and the soil type was also nil for CROPGRO.

\section{FINAL DISCUSSION AND CONCLUSIONS}

A simple model, SOYBEANW, and a comprehensive model, CROPGRO, have been applied to analyse the possible effects of climate change and change in climatic variability on soya bean production in the EU. The comparison of the results from the 2 models indicated the differences in their model approaches and the sort of environmental conditions, in which the model results differed and may become less reliable (Wolf 2002).

Both models calculated for the climate change scenarios at Oxford a strong increase in irrigated seed yield. This yield increase was caused by both temperature rise and increased atmospheric $\mathrm{CO}_{2}$. For Montpellier and Seville, however, CROPGRO calculated a considerable increase in irrigated yield for these scenarios, mainly due to increased $\mathrm{CO}_{2}$, whereas SOYBEANW calculated only a slight increase. This difference in yield increase can be explained from the higher optimal temperature for irrigated seed production in CROPGRO (Wolf 2002), resulting in a more positive or a less negative temperature effect on yield. Without irrigation, the seed yield increase for the climate change scenarios was almost identical for the 2 models, i.e. considerable, slight and nil for Oxford, Montpellier and Seville, respectively. Changes in climatic variability in the scenarios did not result in a yield change at any site, both with and without irrigation and for both CROPGRO and SOYBEANW. For other crops, such as potatoes, changes in climatic variability in the EU also did not result in a yield change (Wolf 2000b). 
A comparable scenario analysis was done with CROPGRO for soya bean production at a number of sites in the USA (Curry et al. 1995). In this study, irrigated seed yields also increased more strongly by climate change at sites where present temperatures were relatively low. In addition, climate change scenarios that gave relatively small or large temperature increases resulted in respectively large and small increases (or even decreases) in irrigated seed yields in the USA. In the present study, however, the increase in irrigated seed yield at Seville for the HCGS climate change scenario was only slightly stronger than that for the warmer HCGG scenario. In another scenario analysis for the USA, Haskett et al. (1997) showed that the increase in atmospheric $\mathrm{CO}_{2}$ that accompanied the climate change primarily caused the increases in seed yield, just as in the present study. Such a yield increase, however, only occurred if the change in climate conditions was not too strong and destructive (e.g. extreme temperatures or drought).

The coefficient of yield variation (CV) is a good indicator of the yield variability between years and the risk of a relatively low yield. Climate change and changes in climatic variability may cause changes in the $\mathrm{CV}$ of seed yield. Both models calculated very low values for the CV of irrigated seed yields under the baseline climate at Montpellier and Seville. This shows that optimal conditions for soya bean production (i.e. low risk for yield reduction by, for example, low temperatures) occur at present at these sites. The $\mathrm{CV}$ values did not change with climate change. For Oxford, which is rather cool for soya bean production, both models calculated relatively high CV values for irrigated production, due to yield reductions in cold years. These CV values decreased with a change in the climate, becoming warmer and thus more favourable for soya bean production. Without irrigation, the CV of seed yield under the baseline climate at all sites was moderately high (which mainly reflects the moderate risk for yield reduction by drought) from both models, and the change in CV by climate change was variable depending on site, climate change scenario and model. In the USA, the CV of soya bean yields increased with climate change and in particular for production without irrigation (Curry et al. 1995), partly due to a decrease in mean yield. This shows that this future climate is less favourable for soya bean production, becoming hot, in particular in southern USA, and more dry. Changes in climatic variability did not change CV values for irrigated seed yields from both CROPGRO and SOYBEANW and resulted in similar or moderately lower CV values for the water-limited yields. For other crops, such as potatoes, changes in climatic variability in the EU also almost did not change the CV of yields (Wolf 2000b).
The effectiveness of changes in crop management (i.e. variety, sowing date, irrigation) in response to climate change was analysed for Seville. The impact of the crop variety on yield changes due to climate change was small to nil with both models. This indicates that the crop variety need not to be changed in response to climate change. The impact of an earlier sowing date on yield changes by climate change was nil according to both models, when irrigation was applied. For water-limited production, an earlier sowing date resulted in a moderately and considerably higher seed yield for the baseline and scenario climates with CROPGRO and a slightly and moderately higher yield with SOYBEANW. This can be explained from the rainfall distribution at Seville. Precipitation only occurs in winter, and, with early crop emergence, a larger part of it can be used by the crop. In addition, early crop emergence resulted in an advanced period of seed filling, in which growth reduction by drought was less. The results from both models showed that for water-limited production the yield increase due to climate change became stronger for an advanced sowing date, and in particular with CROPGRO due to its stronger yield sensitivity to drought, and that in response to climate change an earlier sowing date was required. Irrigation requirements both increased and decreased with climate change depending on the site, the crop model and the climate change scenario, if sowing occurred in the present day. However, the irrigation requirements always decreased with climate change if a much earlier sowing date was used. This showed again the need for an advanced sowing date with climate change. For potatoes too, this need for advancing the planting date under climate change conditions in the EU, resulting in decreased irrigation requirements and stronger tuber yield increases (Wolf 2000b), was computed. For climate change conditions in the USA, Easterling et al. (1992b) also calculated positive yield changes for maize, soya bean and sorghum from advancing their sowing dates.

Uncertainties in the results from this climate change impact study have been analysed for Seville. Such uncertainties arise from the quality of input data (e.g. weather and soil data), the assumed crop management, and the model structure and sensitivity. Yield sensitivities to changes in most weather variables were practically the same for the 2 models. Important model differences, however, were the higher optimum temperature for irrigated seed production and the stronger seed yield reduction by water shortage in CROPGRO than in SOYBEANW (Wolf 2002). Uncertainties caused by the assumed crop management (e.g. sowing date) were described in Section 3.3. For example, uncertainty in crop variety had no influence on the calculated yield change due to climate change. The inter- 
action between calculated yield change due to climate change and the soil type was practically nil for SOYBEANW (for CROPGRO this could not be determined). This indicated that uncertainty in soil characteristics had almost no influence on the calculated yield change. For elaborate information on the various sources of uncertainty in climate change scenarios (e.g. uncertainty in greenhouse gas emission scenarios, in climate sensitivity to increasing greenhouse gas concentrations, in climate change patterns over Europe, and in changes in climatic variability) and in results from climate change impact studies (e.g. uncertainty in model approach, model parameterization and calibration, and input data that in particular increases in climate studies at the larger scale, such as studies on arable crop production in a changed climate in Denmark [Olesen et al. 2000] and Finland [Carter et al. 2000]), see the proceedings of the ECLAT-2 workshop (Carter et al. 1999).

Acknowledgements. The author is grateful to Dr J. W. Jones (Agricultural and Biological Engineering Department, University of Florida, Gainesville, USA) for providing the CROPGRO model and the preliminary version of its technical documentation, to Dr T. R. Sinclair (Agronomy Physiology Department, University of Florida, Gainesville, USA) for providing his soya bean model and related information, to Dr A. Bouniols (INRA, Station d'Agronomie, Auzeville, France) for providing information on the soya bean experiments at Toulouse, to all colleagues within the EU project CLIVARA (see Downing et al. 2000) for their collaboration and in particular to Elaine Barrow (Climatic Research Unit, University of East Anglia, UK) for providing the climate change scenarios. This work was funded by the Commission of the European Communities' Environment Programme (contract ENV4-CT95-0154).

\section{LITERATURE CITED}

Adams RM, Rosenzweig C, Peart RM, Ritchie JT, McCarl BA, Glyer JD, Curry RB, Jones JW, Boote KJ, Allen LH (1990) Global climate change and US agriculture. Nature 345: 219-223

Barrow EM, Hulme M, Semenov MA, Brooks RJ (2000) Climate change scenarios. In: Downing TE, Harrison PA, Butterfield RE, Lonsdale KG (eds) Climate change, climatic variability and agriculture in Europe: an integrated assessment. Research report no. 21, Environmental Change Institute, University of Oxford, p 11-27

Boote KJ, Jones JW, Hoogenboom G (1998a) Simulation of crop growth: CROPGRO model. In: Peart RM, Curry RB (eds) Agricultural systems modeling and simulation. Marcel Dekker Inc, New York, p 651-692

Boote KJ, Jones JW, Hoogenboom G, Pickering NB (1998b) The CROPGRO model for grain legumes. In: Tsuji GY, Hoogenboom G, Thornton PK (eds) Understanding options for agricultural production. Kluwer Academic Publishers, Dordrecht, p 99-128

Carter TR, Hulme M, Viner D (eds) (1999) Representing uncertainty in climate change scenarios and impact studies. Proc ECLAT-2 workshop, report no. 1, Helsinki, Climatic Research Unit, University of East Anglia, Norwich
Carter TR, Saarikko RA, Joukainen SKH (2000) Modelling climate change impacts on wheat and potato in Finland. In: Downing TE, Harrison PA, Butterfield RE, Lonsdale KG (eds) Climate change, climatic variability and agriculture in Europe: an integrated assessment. Research report no. 21, Environmental Change Institute, University of Oxford, p 289-312

Colson J (1992) Developpement reproducteur du sojaimpact des conditions de culture et modelisation du potentiel de production varietal. PhD thesis, University Paul Sabatier, Toulouse

Colson J, Bouniols A, Jones JW (1995) Soybean reproductive development: adapting a model for European cultivars. Agron J 87:1129-1139

Curry RB, Peart RM, Jones JW, Boote KJ, Allen LH (1990) Response of crop yield to predicted changes in climate and atmospheric $\mathrm{CO}_{2}$ using simulation. Trans Am Soc Agron Eng 33:1383-1390

Curry RB, Jones JW, Boote KJ, Peart RM, Allen LH, Pickering NB (1995) Response of soybean to predicted climate change in the USA. In: Climate change and agriculture: analysis of potential international impacts. ASA special publication no. 59, American Society of Agronomy, Madison, p 163-182

Downing TE, Harrison PA, Butterfield RE, Lonsdale KG (eds) (2000) Climate change, climatic variability and agriculture in Europe: an integrated assessment. Research report no. 21, Environmental Change Institute, University of Oxford

Easterling WE, McKenney MS, Rosenberg NJ, Lemon KM (1992a) Simulations of crop response to climate change: effects with present technology and no adjustments (the 'dumb farmer' scenario). Agric For Meteorol 59:53-73

Easterling WE, Rosenberg NJ, Lemon KM, McKenney MS (1992b) Simulations of crop responses to climate change: effects with present technology and currently available adjustment (the 'smart farmer' scenario). Agric For Meteorol 59:75-102

Egli DB, Bruening W (1992) Planting date and soybean yield: Evaluation of environmental effects with a crop simulation model: SOYGRO. Agric For Meteorol 62:19-29

Haskett JD, Pachepsky YA, Acock B (1997) Increase of $\mathrm{CO}_{2}$ and climate change effects on Iowa soybean yield, simulated using GLYCIM. Agron J 89:167-176

Hoogenboom G, Tsuji GY, Pickering NB, Curry RB, Jones JW, Singh U, Godwin DG (1995) Decision support system to study climate change impacts on crop production. In: Climate change and agriculture: analysis of potential international impacts. ASA special publication no. 59, American Society of Agronomy, Madison, p 51-75

Hoogenboom G, Boote KJ, Jones JW (1997) Modeling and risk management of soybean. In: Proc World Soybean Research Conference, 1994. Kasetsart University Press, Bangkok, p 292-298

Johns TC, Carnell RE, Crossley JF, Gregory JM, Mitchell JFB, Senior TA, Tett S, Wood RA (1997) The second Hadley Centre coupled ocean-atmosphere GCM: model description, spinup and validation. Clim Dyn 13:103-134

Jones JW, Ritchie JT (1991) Crop growth models. In: Management of farm irrigation systems. American Society of Agricultural Engineers, St. Joseph, p 69-98

Jones JW, Boote KJ, Hoogenboom G, Jagtap SS, Wilkerson GG (1989) SOYGRO V5.42, Soybean crop growth simulation model, User's guide. Florida Agric Exp Stn Journal no. 8304, International Benchmark Sites Network for Agrotechnology Transfer (IBSNAT) and University of Florida, Gainesville 
Lal M, Singh KK, Srinivasan G, Rathore LS, Naidu D, Tripathi CN (1999) Growth and yield responses of soybean in Madhya Pradesh, India to climate variability and change. Agric For Meteorol 93:53-70

Magrin GO, Travasso MI, Diaz RA, Rodriguez RO (1997) Vulnerability of the agricultural systems of Argentina to climate change. Clim Res 9:31-36

Mearns LO (2000) Climatic change and variability. In: Reddy KR, Hodges HF (eds) Climate change and global crop productivity. CABI Publishing, Wallingford, p 7-35

Mitchell JFB, Johns TC, Gregory JM, Tett S (1995) Climate response to increasing levels of greenhouse gases and sulphate aerosols. Nature 376:501-504

Muchow RC, Sinclair TR (1986) Water and nitrogen limitations in soybean grain production. II. Field and model analyses. Field Crop Res 15:143-156

Nagarajan K, O'Neil RJ, Lowenberg-DeBoer J, Edwards CR (1993) Indiana Soybean system model (ISSM): I. Crop model evaluation. Agric Syst 43:357-379

Olesen JE, Jensen T, Bøcher PK (2000) Modelling climate change impacts on wheat and potato in Denmark. In: Downing TE, Harrison PA, Butterfield RE, Lonsdale KG (eds) Climate change, climatic variability and agriculture in Europe: an integrated assessment. Research report no. 21, Environmental Change Institute, University of Oxford, p 313-332

Phillips DL, Lee JJ, Dodson RF (1996) Sensitivity of the US corn belt to climate change and elevated $\mathrm{CO}_{2}$ : I. Corn and soybean yields. Agric Syst 52:481-502

Pickering NB, Jones JW, Boote KJ (1995) Adapting SOYGRO V5.42 for prediction under climate change conditions. In: Climate change and agriculture: analysis of potential international impacts, ASA special publication no. 59, American Society of Agronomy, Madison, p 77-98

Rind D, Goldberg R, Ruedy R (1989) Change in climate variability in the 21st century. Clim Change 14:5-37

Semenov MA, Barrow EM (1997) Use of a stochastic weather generator in the development of climate change scenarios. Clim Change 35:397-414

Editorial responsibility: Gerd Esser,

Gießen, Germany
Semenov MA, Porter JR (1995) Climatic variability and the modelling of crop yields. Agric For Meteorol 73:265-283

Semenov MA, Wolf J, Evans LG, Eckersten H, Iglesias A (1996) Comparison of wheat simulation models. II. Application of climate change scenarios. Clim Res 7: $271-281$

Sinclair TR (1986) Water and nitrogen limitations in soybean grain production. I. Model development. Field Crop Res 15:125-141

Sinclair TR, Rawlins SL (1993) Inter-seasonal variation in soybean and maize yields under global environmental change. Agron J 85:406-409

Sinclair TR, Salado-Navarro L, Morandi EN, Bodrero ML, Martignone RA (1992) Soybean yield in Argentina in response to weather variation among cropping seasons. Field Crop Res 30:1-11

Spaeth SC, Sinclair TR, Ohnuma T, Konno S (1987) Temperature, radiation, and duration dependence of high soybean yields: measurement and simulation. Field Crop Res 16: 297-307

Tsuji GY, Uehara G, Balas S (1994) DSSAT version 3, a decision support system for agrotechnology transfer. International Benchmark Sites Network for Agrotechnology Transfer (IBSNAT), University of Hawaii, Honolulu

Wolf J (2000a) Modelling climate change impacts on soya bean in south-west Spain. In: Downing TE, Harrison PA, Butterfield RE, Lonsdale KG (eds) Climate change, climatic variability and agriculture in Europe: an integrated assessment. Research report no. 21, Environmental Change Institute, University of Oxford, p 217-237

Wolf J (2000b) Modelling climate change impacts at the site scale on potato. In: Downing TE, Harrison PA, Butterfield $\mathrm{RE}$, Lonsdale KG (eds) Climate change, climatic variability and agriculture in Europe: an integrated assessment. Research report no. 21, Environmental Change Institute, University of Oxford, p 135-154

Wolf J (2002) Comparison of two soya bean simulation models under climate change. I. Model calibration and sensitivity analyses. Clim Res 20:55-70

Submitted: November 30, 2000; Accepted: June 30, 2001

Proofs received from author(s): December 18, 2001 